\title{
Role of Selective $\alpha$ and $\beta$ Adrenergic Receptor Mechanisms in Rat Jejunal Longitudinal Muscle Contractility
}

\author{
Roland Seiler • Andreas Rickenbacher • Sidney Shaw • \\ Simon Haefliger • Bruno M. Balsiger
}

Received: 29 August 2007 / Accepted: 5 September 2007 / Published online: 19 September 2007

(C) 2007 The Society for Surgery of the Alimentary Tract

\begin{abstract}
Gut motility is modulated by adrenergic mechanisms. The aim of our study was to examine mechanisms of selective adrenergic receptors in rat jejunum. Spontaneous contractile activity of longitudinal muscle strips from rat jejunum was measured in 5-ml tissue chambers. Dose-responses (six doses, $10^{-7}-3 \times 10^{-5} \mathrm{M}$ ) to norepinephrine (NE, nonspecific), phenylephrine $\left(\mathrm{PH}, \alpha_{1}\right)$, clonidine $\left(\mathrm{C}, \alpha_{2}\right)$, prenalterol $\left(\mathrm{PR}, \beta_{1}\right)$, ritodrine $\left(\mathrm{RI}, \beta_{2}\right)$, and ZD7714 $\left(\mathrm{ZD}, \beta_{3}\right)$ were evaluated with and without tetrodotoxin (TTX, nerve blocker). NE $\left(3 \times 10^{-5} \mathrm{M}\right)$ inhibited $74 \pm 5 \%$ (mean \pm SEM) of spontaneous activity. This was the maximum effect. The same dose of $\mathrm{RI}\left(\beta_{2}\right), \operatorname{PH}\left(\alpha_{1}\right)$, or $\mathrm{ZD}\left(\beta_{3}\right)$ resulted in an inhibition of only $56 \pm 5$, $43 \pm 4,33 \pm 6$, respectively. The calculated concentration to induce $50 \%$ inhibition (EC50) of $\mathrm{ZD}\left(\beta_{3}\right)$ was similar to NE, whereas higher concentrations of $\operatorname{PH}\left(\alpha_{1}\right)$ or $\operatorname{RI}\left(\beta_{2}\right)$ were required. $\mathrm{C}\left(\alpha_{2}\right)$ and $\operatorname{PR}\left(\beta_{1}\right)$ had no effect. TTX changed exclusively the EC50 of RI from $4.4 \pm 0.2$ to $2.7 \pm 0.8 \%(p<0.04)$. Contractility was inhibited by NE (nonspecific). PH $\left(\alpha_{1}\right), \operatorname{RI}\left(\beta_{2}\right)$, and $\operatorname{ZD}\left(\beta_{3}\right)$ mimic the effect of NE. TTX reduced the inhibition by RI. Our results suggest that muscular $\alpha_{1}$, $\beta_{2}$, and $\beta_{3}$ receptor mechanisms mediate adrenergic inhibition of contractility in rat jejunum. $\beta_{2}$ mechanisms seem to involve also neural pathways.
\end{abstract}

Keywords Contractility · Motility · Jejunum $\cdot$ Rat $\cdot$ In vitro · Adrenergic $\cdot$ Adrenergic receptor $\cdot \alpha$-Adrenergic receptors $\cdot \beta$-Adrenergic receptors

Part of this work was presented as a poster at the annual meeting of the Society for Surgery of the Alimentary Tract, Orlando, FL, May 17-22, 2003, and published as an abstract in Gastroenterology 2003, 124(4):M1342.

R. Seiler $\cdot$ A. Rickenbacher $\cdot$ S. Haefliger $\cdot$ B. M. Balsiger

Gastroenterology Unit (Prof. U. Scheurer),

University Hospital Bern, University of Bern,

Bern, Switzerland

S. Shaw

Department of Clinical Research, University Hospital Bern, University of Bern,

Bern, Switzerland

B. M. Balsiger $(\square)$

Department of Internal Medicine, Spitalnetzbern,

Tiefenau Hospital,

Tiefenaustrasse 112,

3004 Bern, Switzerland

e-mail: bruno.balsiger@spitalnetzbern.ch

\section{Introduction}

The modulation of gastrointestinal muscular activity is dependent on the interaction of two complex neural networks, the central nervous system with the extrinsic nerves (vagal, sympathetic) that connect with the enteric nervous system, which is completely intrinsic within the bowel wall. ${ }^{1}$ In the gastrointestinal tract, interaction between the central nervous system and the enteric nervous system is important for the response to stress, for eating, and for behavior. ${ }^{2}$

The upper gastrointestinal tract and the distal colon and rectum are mainly modulated by vagal motor pathways. In the small bowel, vagal input is supplied to myenteric neurons, ${ }^{3}$ which influence the generation of motor patterns.

The nerve cell bodies of the intestinal sympathetic nervous system are located in the prevertebral ganglia, and enter the gut with their postganglionic fibers. In the gut wall, no adrenergic nerve cell bodies are present. ${ }^{1}$ Most if not all sympathetic postganglionic fibers affecting motility are thought to synapse in the enteric nervous system and 
not directly on smooth muscle cells. Indeed, no synapses exist between adrenergic nerves and the nonsphincter muscle cells in the gut. ${ }^{4}$ In earlier research, despite the predominant, direct adrenergic input to the enteric nervous system, we found strong, adrenergic inhibitory motor mechanisms in rat jejunum and ileum occurring preferentially at the level of these smooth muscle cells rather than in the enteric nervous system; ${ }^{5,6}$ these effects appeared to be independent of input from the enteric nervous system.

Directing pharmacologic therapy at the receptors occurring on smooth muscle cells in the gut could therefore be one approach to target gastrointestinal motility disorders through adrenergic pathways. Up to now, treatments targeting adrenergic pathways in the gastrointestinal tract have not been successful. One reason is that the agents used produce substantial cardiovascular side effects. ${ }^{7}$ Therefore, mechanisms and pathways of specific subtypes of adrenergic receptors involved in modulating contractile activity of the gut are of considerable interest.

The effect of selective stimulation of $\beta$-adrenergic receptors, especially the effect of $\beta_{3}$ receptor agonists on contractile activity in rat jejunal longitudinal muscle, has not yet been examined. In the rat ileum, we previously showed the importance of $\beta_{3}$ receptor mechanisms for contractile activity. ${ }^{8}$

In the current study, our first aim was to identify the effect of the stimulation of all subtypes of adrenergic receptors on jejunum longitudinal smooth muscle of the rat. Our second aim was to determine if these receptor-specific mechanisms were mediated at the level of the smooth muscle and/or via the enteric nervous system. Our hypothesis, based also on our findings in the rat ileum, ${ }^{8}$ was that $\alpha_{1}, \beta_{2}$, and $\beta_{3}$ receptor mechanisms all mediate inhibitory responses and that these mechanisms are active directly at the level of the smooth muscle and not indirectly via effects mediated through the enteric nervous system.

\section{Materials and Methods}

\section{Preparation of Tissue}

Procedures and animal care were performed according to the guidelines of the Department of Agriculture of the Canton of Bern, Switzerland. Male Wistar rats were used in all experiments. Anesthesia was achieved by intraperitoneal sodium pentobarbital $(5 \mathrm{mg} / 100 \mathrm{~g}$; Abbott Laboratories, North Chicago, IL). A 5-cm segment of the jejunum was removed, beginning $2 \mathrm{~cm}$ anal to the ligament of Treitz, and stored in cold Krebs-Ringer's buffer (concentration in mM: $\mathrm{NaCl} 118.3, \mathrm{KCl}$ 4.7, $\mathrm{CaCl}_{2} 2.5, \mathrm{MgSO}_{4} 1.2, \mathrm{KH}_{2} \mathrm{PO}_{4} 1.2$, $\mathrm{NaHCO}_{3} 25.0$ calcium disodium edetate 0.26 , and glucose 11.1). The proximal end of the specimen was marked.
Recording of Contractile Activity

The segment of the proximal jejunum was immersed in chilled, modified Krebs-Ringer's bicarbonate solution and opened along the mesenteric border. The tissue was pinned flat in a Petri dish, and eight full-thickness muscle strips per rat were prepared in the direction of the longitudinal muscle layer. Silk loops were tied at both ends of the strips. The muscles were suspended vertically in 5-ml organ chambers (Radnoti Glass Technology, Monrovia, CA) filled with modified Krebs-Ringer's bicarbonate solution maintained at $37.5^{\circ} \mathrm{C}$. The solution was bubbled with $95 \% \mathrm{O}_{2}$ and $5 \% \mathrm{CO}_{2}$ (Carbagas, Bern, Switzerland). The lower end of the muscle strip was connected to a fixed glass hook in the chamber, while the upper end was attached to a noncompliant force transducer (Radnoti Glass Technology), thereby allowing measurement of isometric force.

\section{Experimental Design}

After an equilibration period of $80-90 \mathrm{~min}$, with buffer solution changed every $20-25 \mathrm{~min}$, each strip was stretched incrementally at $10-15$-min intervals to its optimal length $\left(L_{\mathrm{o}}\right) . L_{\mathrm{o}}$ is defined as the length beyond which further stretching did not increase the amplitude of spontaneous contractions. The entire experiment was then performed at this $L_{\mathrm{o}}$; strips without spontaneous activity were not used ( $2 \%$ of all muscle strips).

After baseline spontaneous activity was recorded, one substance per chamber was administered in a cumulative manner. Norepinephrine (NE) was chosen as the nonselective adrenergic agonist, phenylephrine and clonidine as $\alpha_{1}$ and $\alpha_{2}$-selective agonists, and prenalterol, ritodrine, and

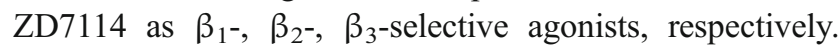
Drugs were added in six cumulative doses (range $1 \times 10^{-7}$ $3 \times 10^{-5} \mathrm{M}$ ) every $10 \mathrm{~min}$. The highest dose used was $3 \times$ $10^{-5} \mathrm{M}$, according to our previous work using only NE. ${ }^{5,6}$ One chamber contained a control strip to confirm stable activity for the duration of the experiment, and the last chamber contained a spare strip.

After the dose-response experiment, the chambers were washed four times with modified Krebs-Ringer's buffer. When spontaneous contractions returned to baseline activity, tetrodotoxin (TTX; $1 \times 10^{-6} \mathrm{M}$ ) was added to every chamber. TTX is thought to abolish almost all enteric neural input by blocking neuronal sodium channels. After a 15-20-min equilibration period, the same dose-response experiment was repeated in each chamber with the same agonist.

At the conclusion of the experiment, the length of each strip between the two ties of silk loops and wet weight were measured. 
Data Analysis

Total spontaneous contractile activity was quantified as the integral of the generated force $(g \times$ time as total area under the contractile curve) measured for $5 \mathrm{~min}$ at $L_{\mathrm{o}}$, while responses to adrenergic agonists were quantified by measuring the integral of force for $5 \mathrm{~min}$ immediately after drug administration. The integral of force was calculated by computerized methodology using a special software (AcqKnowledge, Biopac Systems, Goleta, CA), normalized per millimeter squared of cross-sectional area (CSA) for each muscle strip.

The CSA was calculated using the following equation:

$$
\begin{aligned}
\operatorname{CSA}\left(\mathrm{mm}^{2}\right)= & \text { tissue wet weight }(\mathrm{mg}) / \text { tissue length }(\mathrm{mm}) \\
& \times \text { tissue density }\left(\mathrm{mg} / \mathrm{mm}^{3}\right)
\end{aligned}
$$

Tissue length and weight were measured at the end of the experiment, and smooth muscle tissue density was assumed to be $1.05 \mathrm{mg} / \mathrm{mm}^{3}$.

The dose-response curve for each agonist was obtained by defining spontaneous contractile activity as $100 \%$. To quantify these dose-response curves, the negative of the natural $\log (\ln )$ of the equipotent concentration that caused a $50 \%$ response $\left(\mathrm{EC}_{50}\right)$ was estimated for each agonist based on the dose-response curve. A greater $\mathrm{EC}_{50}$ represents a smaller concentration of an agonist needed to induce $50 \%$ inhibition of spontaneous activity.

Values are presented as mean \pm standard error of the mean (SEM). Student's $t$ tests with a Bonferroni correction were used to compare the effects of each specific agonist with spontaneous activity at all doses and the respective effect of NE. The effect of TTX on spontaneous activity, on $\mathrm{EC}_{50}$, and on each dose of the respective agonist was evaluated in the same way.

Changes of the amplitude were analyzed as follows. The amplitude after the highest dose of each agonist without TTX was calculated as a percentage of the amplitude at $L_{\mathrm{o}}$. After the second dose-response with a neural blockade, the amplitude after the highest dose was calculated as a percentage of the amplitude after the equilibration with $\operatorname{TTX}\left(L_{\text {oTTX}}\right)$.

\section{Drugs}

L-Phenylephrine hydrochloride, clonidine hydrochloride, ritodrine hydrochloride, and NE bitartarate salt were purchased from Sigma (St. Louis, MO). Prenalterol and ZD7114 hydrochloride were purchased from Astra Zeneca (Södertälje, Sweden). TTX was purchased from Juro (Luzern, Switzerland).

\section{Results}

Spontaneous Contractile Activity

Spontaneous phasic contractile activity was recorded shortly after suspending the muscle strips in the organ chambers. After the addition of TTX (after the first adrenergic dose-response experiments, washout, and restoration of spontaneous activity), contractile activity remained the same $\left(92.7 \pm 4\right.$ to $\left.88.1 \pm 4 \mathrm{~g} / 5 \mathrm{~min} / \mathrm{mm}^{2} ; p>0.05\right)$.

\section{Effect of Nonselective Adrenergic Stimulation}

In all strips treated with NE, the amplitude and the baseline tone were reduced in a dose-dependent manner, while the frequency of contractions remained unchanged. At the higher doses, an initial increase in basal tone was observed (Fig. 1a). Inhibition of spontaneous contractile activity induced by the highest dose of NE $\left(3 \times 10^{-5} \mathrm{M}\right)$ was $73.7 \pm$ $5 \%$. Blocking all neural activity within the bowel wall with TTX $\left(1 \times 10^{-6} \mathrm{M}\right)$ changed neither the dose response to NE (Table 1) nor the effect of the highest dose of NE on the reduction in the amplitude (Table 2).

\section{Effect of $\alpha$-Agonists}

Phenylephrine ( $\alpha_{1}$-agonist) inhibited contractile activity by reducing the area under the curve but not the basal tone in a dose-dependent fashion (Fig. 1). However, the $\mathrm{EC}_{50}$ was less than for $\mathrm{NE}$, and the inhibition (at $3 \times 10^{-5} \mathrm{M}$ ) was less compared to an equimolar dose of NE (Table 1; Figs. 1 and 2a). TTX had no effect on $\alpha_{1}$ receptor-mediated inhibition induced by phenylephrine. Neither the reduction in the area under the curve nor the change of basal tone was dependent

\section{a}



Norepinephrine

b

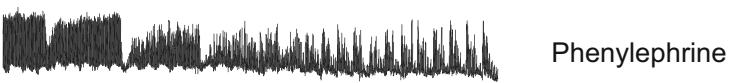

\section{C}

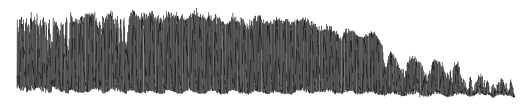

Ritodrine

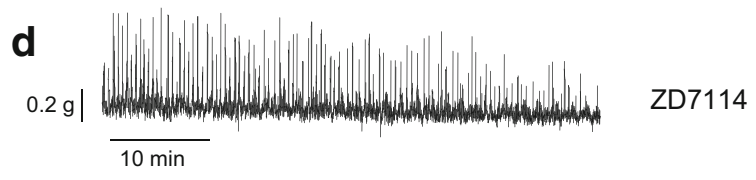

Figure 1 Effect of a norepinephrine, b phenylephrine $\left(\alpha_{2}\right)$, c ritodrine $\left(\beta_{2}\right)$, and d ZD7114 $\left(\beta_{3}\right)$ on spontaneous activity. Cumulatively administered molar doses of agents caused a dosedependent decrease in contractile activity. 
Table 1 Inhibitory Effect of Selective Adrenergic Agonists on Rat Jejunal Longitudinal Muscle without and with Tetrodotoxin (TTX; $\left.10^{-6} \mathrm{M}\right)$

\begin{tabular}{|c|c|c|c|c|}
\hline & \multicolumn{2}{|c|}{ Response to $3 \times 10^{-5} \mathrm{M}$ dose $\mathrm{e}^{\mathrm{a}}$} & \multicolumn{2}{|l|}{$\mathrm{EC}_{50}$} \\
\hline & without TTX & with TTX & without TTX & with TTX \\
\hline Norepinephrine & $74 \pm 5^{*}$ & $81 \pm 4^{*}$ & $5.6 \pm 0.2$ & $5.8 \pm 0.1$ \\
\hline Phenylephrine, $\alpha_{1} \alpha_{1}$ & $43 \pm 4 * * *$ & $42 \pm 5^{*}, * *$ & $1.9 \pm 0.8^{* *}$ & $2.2 \pm 0.9 * *$ \\
\hline Clonidine, $\alpha_{2}$ & $1 \pm 9 * *$ & $16 \pm 5^{*}, * *$ & NA & NA \\
\hline Prenalterol, $\beta_{1}$ & $5 \pm 6^{* *}$ & $19 \pm 4^{*}, * *$ & NA & NA \\
\hline Ritodrine, $\beta_{2}$ & $56 \pm 5^{*}$ & $44 \pm 10^{*}, * *$ & $4.4 \pm 0.2^{* *}$ & $2.7 \pm 0.8 * *, * * *$ \\
\hline $\mathrm{ZD} 7114, \beta_{3}$ & $33 \pm 6^{*}, * *$ & $37 \pm 7 *, * *$ & $5.8 \pm 2$ & $3.5 \pm 0.4^{* *}$ \\
\hline
\end{tabular}

NA Not applicable, as no inhibition was seen

${ }^{*} p<0.006$ compared to spontaneous activity before adding respective drug

$* * p<0.05$ to $\mathrm{NE}$

$* * * p<0.05$ to $\mathrm{EC}_{50}$ without TTX

${ }^{\mathrm{a}}$ Values: percent inhibition, mean $\pm \mathrm{SEM} ; n=10$ rats; $\mathrm{EC}_{50}$ represents calculated negative $\log$ of molar value resulting in $50 \%$ inhibition of spontaneous activity.

on presynaptic mechanisms (Tables 2 and 3). Clonidine ( $\alpha_{2}$-agonist) with and without TTX had no demonstrable effect on contractile activity.

\section{Effect of $\beta$-Agonists}

Differing effects of the three $\beta$-adrenergic agonists were noted. Prenalterol ( $\beta_{1}$-agonist) with or without TTX had no effect. In contrast, ritodrine ( $\beta_{2}$-agonist) and ZD7114 $\left(\beta_{3^{-}}\right.$ agonist) both induced a marked dose-dependent inhibition of $56 \pm 5$ and $44 \pm 10 \%$ at the highest dose $\left(3 \times 10^{-5} \mathrm{M}\right)$, respectively (Table 1, Fig. 2b). At smaller concentrations, the inhibition induced by ZD7114 was even stronger compared to NE (Fig. 2b). TTX did not influence the dose-response of ZD7114 ( $\beta_{3}$-agonist), but it decreased the inhibition of ritodrine ( $\beta_{2}$-agonist). This effect seems to be due primarily to a smaller reduction in the amplitude. (Tables 2 and 3, Fig. $3)$. Ritodrine without TTX $\left(3 \times 10^{-5} \mathrm{M} ; \beta_{2}\right.$-agonist $)$ reduced the amplitude by $60 \pm 6 \%$ compared to the amplitude at $L_{\mathrm{o}}$.

Table 2 Reduction in Amplitude Induced by Adrenergic Agonist without or with Tetrodotoxin (TTX; $10^{-6} \mathrm{M}$ )

\begin{tabular}{lll}
\hline & \multicolumn{2}{l}{ Response to $3 \times 10^{-5} \mathrm{M}$ dose } \\
\cline { 2 - 3 } & Without TTX & With TTX \\
\hline Norepinephrine & $33 \pm 8$ & $15 \pm 2^{* * *}$ \\
Phenylephrine, $\alpha_{1}$ & $79 \pm 4$ & $85 \pm 5$ \\
Clonidine, $\alpha_{2}$ & $91 \pm 6$ & $99 \pm 4$ \\
Prenalterol, $\beta_{1}$ & $100 \pm 10$ & $97 \pm 12$ \\
Ritodrine, $\beta_{2}$ & $\mathbf{4 0} \pm \mathbf{6}$ & $\mathbf{5 7} \pm \mathbf{5}^{*}$ \\
ZD7114, $\beta_{3}$ & $80 \pm 6$ & $66 \pm 6$ \\
\hline
\end{tabular}

$* p<0.05$ vs without TTX

$* * p=0.055$ vs without TTX

${ }^{\text {a }}$ Values represent percent (mean \pm SEM; $n=10$ rats) of amplitude after the highest dose of agonist $\left(3 \times 10^{-5} \mathrm{M}\right)$ compared to the amplitude before dose response experiment $(100 \%)$.
In the presence of TTX, the reduction in the amplitude was smaller $(43 \pm 5 \%, p<0.05)$.

The $\mathrm{EC}_{50}$ for ZD7114 did not differ from the $\mathrm{EC}_{50}$ for $\mathrm{NE}(5.8 \pm 2$ vs $5.6 \pm 0.2, p>0.05)$, suggesting a similar molar inhibitory effect of ZD7114. However, the $\mathrm{EC}_{50}$ of ritodrine and $\mathrm{NE}(4.4 \pm 0.2$ vs $5.0 \pm 0.3, p<0.05)$ differed,
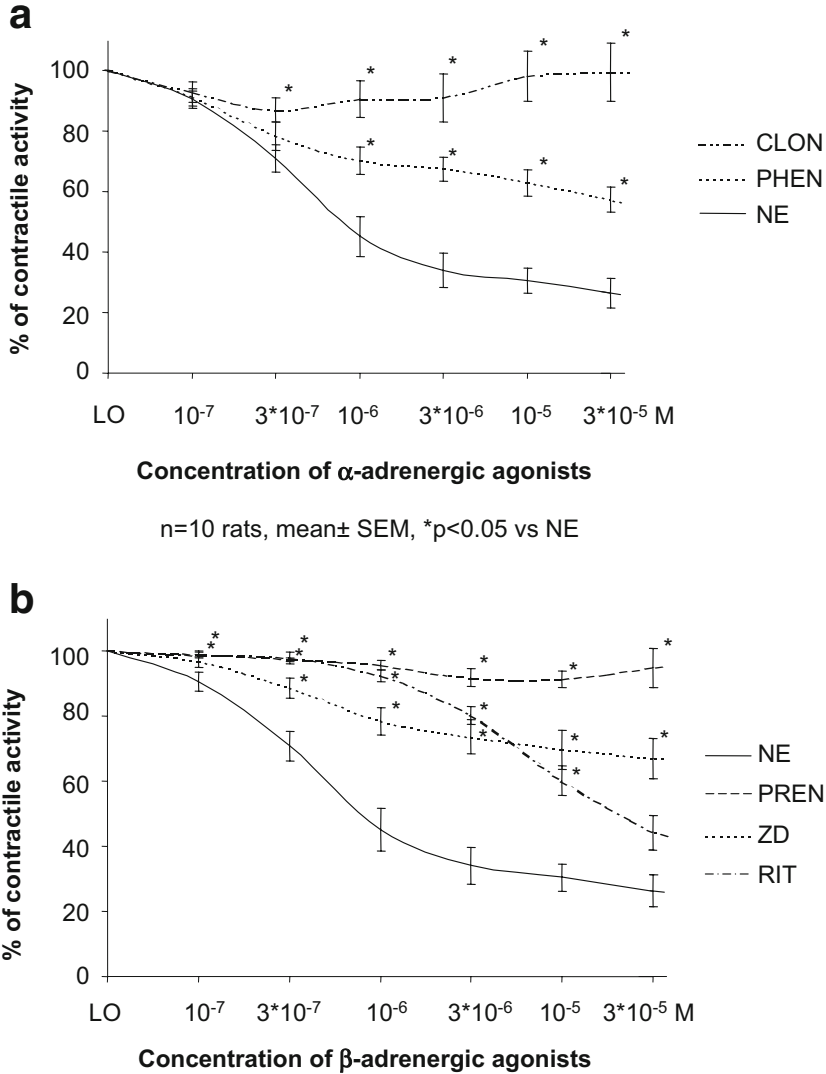

$\mathrm{n}=10$ rats, mean \pm SEM, ${ }^{*} \mathrm{p}<0.05$ vs NE

Figure 2 Dose-responses of a clonidine $\left(\alpha_{1}\right)$ and phenylephrine $\left(\alpha_{2}\right)$ and b prenalterol $\left(\beta_{1}\right)$, ritodrine $\left(\beta_{2}\right)$, and ZD7114 $\left(\beta_{3}\right)$ compared with norepinephrine. Values represent percent mean $\pm \operatorname{SEM}(n=10$ rats). 
Table 3 Reduction in Basal Tone Induced by Adrenergic Agonist without or with Tetrodotoxin (TTX; $10^{-6} \mathrm{M}$ )

\begin{tabular}{lll}
\hline & \multicolumn{2}{l}{ Response to $3 \times 10^{-5} \mathrm{M} \mathrm{dose}^{\mathrm{a}}$} \\
\cline { 2 - 3 } & Without TTX & With TTX \\
\hline Norepinephrine & $76 \pm 9$ & $84 \pm 8$ \\
Phenylephrine, $\alpha_{1}$ & $51 \pm 7$ & $49 \pm 11$ \\
Clonidine, $\alpha_{2}$ & $15 \pm 3$ & $18 \pm 11$ \\
Prenalterol, $\beta_{1}$ & $18 \pm 9$ & $29 \pm 9$ \\
Ritodrine, $\beta_{2}$ & $73 \pm 9$ & $63 \pm 12$ \\
ZD7114, $\beta_{3}$ & $64 \pm 7$ & $63 \pm 12$ \\
\hline
\end{tabular}

${ }^{\mathrm{a}}$ Values represent percent (mean $\pm \mathrm{SEM} ; n=10$ rats) reduction in the baseline tone after the highest dose of agonist $\left(3 \times 10^{-5} \mathrm{M}\right)$ compared to the baseline tone before the dose-response experiment $(100 \%)$.

suggesting that $\beta_{2}$ receptors have a smaller influence. This influence seems to decrease even more after TTX. The dose-response curve of ritodrine under neural blockade with TTX was shifted more to the right, and the $\mathrm{EC}_{50}$ was $2.7 \pm 0.8$, compared to $4.4 \pm 0.2$ for NE $(p<0.05$; Fig. $2 b)$. These findings suggest that there is a neural $\beta_{2}$ receptordependent inhibitory pathway in rat longitudinal jejunum smooth muscle.

\section{Discussion}

We designed our study to characterize the involvement of specific adrenergic $\alpha_{1}, \alpha_{2}, \beta_{1}, \beta_{2}$, or $\beta_{3}$ receptor mechanisms in the inhibition of contractile activity of longitudinal smooth muscle in the rat jejunum. As a potential novel therapeutic target for motility disorders, adrenergic pathways modulating gut motility are of particular interest. The identification of specific receptor subtype mechanisms is required to target effects on intestinal contractile function, possibly minimizing or even avoiding cardiovascular side effects.

Our main findings were that $\alpha_{2}$ and $\beta_{1}$ receptor mechanisms do not appear to be involved in the adrenergic modulation of gut contractile activity in the rat jejunum, either directly on the smooth muscle cells or indirectly via the enteric nervous system. In contrast, $\alpha_{1}, \beta_{2}$, and $\beta_{3}$ pathways reproduced, in part, the inhibition induced by NE, a nonselective, global adrenergic agonist. Blocking enteric neural activity within the muscle strip (with TTX, $10^{-6} \mathrm{M}$ ) reduced only the response of $\beta_{2}$ receptor stimulation, suggesting involvement of enteric neural mechanisms.

Because generally not much is known about the role of $\alpha$ receptors in intestinal contractility, our results with the involvement of $\alpha_{1}$ but not $\alpha_{2}$ receptors in inhibitory modulation of motor activity in the rat jejunum are of special interest. Similar to our findings, Fox et al. ${ }^{10}$ detected an inhibitory effect on contractile activity of $\alpha_{1}$ receptors in rat jejunum. In contrast to our results, Fox et al. ${ }^{10}$ found an $\alpha_{2}$ receptor-mediated inhibition as well. Another group documented the induction of neuronal nitric oxide synthase expression after stimulation of $\alpha_{2}$ receptors in rat jejunum, suggesting a potential inhibitory effect by $\alpha_{2}$ receptors, however, without physiologically measuring the effect on contractile activity. ${ }^{11}$ Sagrada et al., ${ }^{12}$ however, measured an inhibitory influence on contractile activity of $\alpha_{2}$ receptors as well as $\alpha_{1}$ receptors in rat jejunum. This difference can be explained by the fact that they performed an in vivo study where conditions and confounding effects such as circulation are not controlled as well as in vitro in tissue chambers.

Of greatest interest is a comparison of our results with data from human studies. A case report of a patient with pheochromocytoma, in whom paralytic ileus was treated successfully with the $\alpha$ receptor antagonist phentolamine and later with prazosin (a selective $\alpha_{1}$ receptor antagonist), ${ }^{13,14}$ suggests that $\alpha$ mechanisms may be involved in human small bowel contractile activity. It is interesting to note that $\alpha_{2}$ pathways did not seem to play a role in an in vitro study in human tissue. ${ }^{14}$ Therefore, it seems likely that the $\alpha$-adrenergic influence in control of human small bowel contractility is dependent on $\alpha_{1}$ receptors. This is in accordance with our present results in the rat jejunum, where $\alpha_{1}$ mechanisms but not $\alpha_{2}$ pathways appear to influence contractile properties in vitro.

Generally, the role of $\alpha$ receptors seems to differ between species and anatomical regions of the gut. In

a Ritodrine; b Ritodrine with TTX
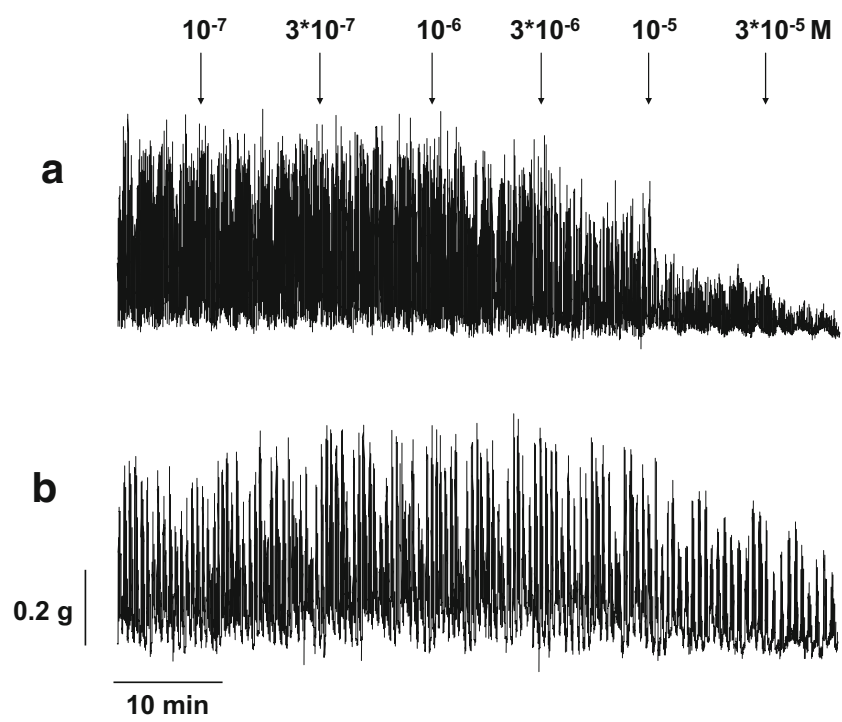

Figure 3 a Effect of ritodrine $\left(R t ; \beta_{2}\right)$ on spontaneous activity. Ritodrine was administered cumulatively and caused a dose-dependent decrease in contractile activity. b In the presence of TTX, the dosedependent reduction in amplitude was smaller, thus reducing the overall inhibitory effect induced by ritodrine. 
rabbit jejunum, only $\alpha_{1}$ but not $\alpha_{2}$ receptors mediate inhibition, ${ }^{15,16}$ and in canine jejunum, equine jejunum, and rat colon, only $\alpha_{2}$ but not $\alpha_{1}$ inhibitory mechanisms have been described. ${ }^{17-21}$ We have previously shown inhibitory $\alpha_{1}$ mechanisms in the rat ileum. ${ }^{8}$ In rabbits, $\alpha_{1}$ mechanisms can be part of inhibitory pathways not only in jejunum but in other anatomic regions of the gut as well. ${ }^{22}$

In our study, inhibitory mechanisms mediated by $\beta_{2}$ adrenergic receptors were identified. These results are in accordance with our findings in rat ileum, where $\beta_{2}$ adrenergic receptors are an important part of inhibitory mechanisms of adrenergic influence. ${ }^{8}$ The finding in the rat jejunum is also consistent with results in rabbit jejunum, 23 whereas in canine jejunum, $\beta_{2}$ pathways had no influence on contractile activity. ${ }^{17}$ Fox et al. ${ }^{10}$ found an inhibitory effect of $\beta$ adrenergic receptors in rat jejunum without conclusively assigning these mechanisms to specific subtypes of $\beta$ adrenergic receptors.

Because $\beta_{3}$ receptors seem to be abundantly present in gastrointestinal tissue, they have been of particular interest. ${ }^{24}$, ${ }^{25}$ Our results are in accordance with our previous study in rat ileum ${ }^{8}$ and with the data of Brown and Summers, ${ }^{26}$ where $\beta_{3}$ pathways are shown to play a major role in the inhibition of rat ileum. In the study of Fox et al., ${ }^{10} \beta_{3}$ pathways could not be selectively examined. Our results suggesting a major inhibitory role of $\beta_{3}$ mechanisms in rat jejunal smooth muscle add important knowledge to rat gut contractile physiology.

In addition, we tried to distinguish between musclerelated mechanisms and pathways involving the enteric nervous system, as under pathologic conditions, adrenergic mechanisms might be compromised at either level of control. $^{5,27,28}$ The pathways of the specific adrenergic $\alpha_{1}$, $\alpha_{2}, \beta_{1}$, or $\beta_{3}$ receptor seem to be independent of the enteric nervous system because none of these mechanisms were sensitive to TTX. It is interesting to note that part of the $\beta_{2}$ inhibition in our experiments appears to be modulated by presynaptic mechanisms. Blockade of neural $\beta_{2}$ mechanisms by TTX resulted in less inhibition of contractile activity. The neurally mediated effect appears to occur by a decreased reduction in amplitude rather than a reduction in baseline tone (Fig. 3). This finding is interesting, as it differs from our results in the rat ileum, where the neural part of $\beta_{2}$ inhibitory mechanisms affected basal tone and not amplitude. This might reflect a different $\beta_{2}$-adrenergic influence in the jejunum compared to the ileum, which is conceivable because global motor patterns (i.e., myoelectric motor complex) change their characteristics from oral to aboral along the small bowel. ${ }^{29,} 30$

Our results are in contrast to the findings of Fox et al., ${ }^{10}$ where presynaptic mechanisms are not involved in $\beta$ adrenergic pathways. This difference could be explained by a different approach of excluding neural input. While they eliminated only the myenteric neurons with an application of benzalkonium chloride to the bowel in an operation 15days before the in vitro experiment, we treated the muscle strips during the experiment with TTX, which represents an acute near-complete abolishment of neural activity.

Whereas in other groups and study designs, no distinction between muscle or neutrally mediated inhibition was made, ${ }^{31}$ we think that such findings are important. Considering gastrointestinal motility disorders in neurological diseases such as diabetic neuropathy or other postneurotomy syndromes (e.g., postvagotomy gastro paresis), it is possible that a lack of neural input could result in impaired modulation of contractile activity by $\beta_{2}$ mechanisms. Thus, further studies are required.

\section{Conclusion}

We conclude that adrenergic inhibition in the rat jejunum may be an additive effect of the three specific adrenergic mechanisms noted to inhibit contractile activity $\left(\alpha_{1}, \beta_{2}\right.$, and $\left.\beta_{3}\right)$. None of the specific pathways alone reached the degree of inhibition achieved by NE. Our previous data in the rat ileum, ${ }^{8}$ other previous results in rabbit ileum, ${ }^{31}$ and studies in human colon by Manara et al. ${ }^{32}$ support this concept of the involvement of several receptors in inhibitory mechanisms.

When we compare our results with the literature, not only the high degree of regional variability (anatomic region and muscle layer) but also differences between species is striking. Regarding differences between anatomic regions, we have now shown that receptor-specific adrenergic inhibitory mechanisms seem to be similar in rat jejunum and rat ileum. In comparison to the human gut, it is of interest that $\alpha_{1}$ receptor mechanisms (but not $\alpha_{2}$ pathways) played a role in our present rat jejunum and previous rat ileum study. ${ }^{8}$ The scarce data from the literature suggest a similar constellation of contractile $\alpha$-adrenergic mechanisms in human small bowel. If this similarity is confirmed in the future, the rat small bowel might be attractive to further model $\alpha_{1}$ pathways in pathologic states.

For $\beta_{2}$ and $\beta_{3}$ receptors, differences between species are evident as well, but we do not have comparable data for human jejunum. Species differences, especially for $\beta_{3}$ pathways, would be of interest, as these receptors are abundantly present in gastrointestinal tissue and are therefore of interest for gastrointestinal motility. ${ }^{33,34}$ Our findings of an important role of inhibitory $\beta_{3}$ mechanisms in rat jejunal contractile activity are novel and add to the understanding of rat small bowel contractile properties. Because we have shown that $\alpha$-adrenergic mechanisms seem to have a similar effect in the rat jejunum and in human jejunum, in future studies, it will be of special interest to address the similarities between rat and human $\beta_{3}$ pathways in jejunal smooth muscle. 
Acknowledgments We thank Jeannie Wurz for her excellent assistance in editing the manuscript. This work was supported by Nycomed AG, Switzerland, by Ethicon, Switzerland, and by the Swiss National Science Foundation (grant no. 31-61583.00 awarded to BMB).

\section{References}

1. Goyal RK, Hirano I. Mechanisms of disease: the enteric nervous system. N Engl J Med. 1996;334:1106-1115.

2. Tache Y, Monnikes H. CRF in the central nervous system mediates stress induced stimulation of colonic motor function: relevance to the pathophysiology of IBS. In: Mayer EA, Raybould HE, editors. Basic and Clinical Aspects of Chronic Abdominal Pain. Amsterdam: Elsevier; 1993. p. 141-151.

3. Kirchgessner AL, Gershon MD. Identification of vagal efferent fibers and putative target neurons in the enteric nervous system of the rat. J Comp Neurol. 1989;285:38-53.

4. Johnson LR, Alpers DH, Christensen J, Jacobson ED, Walsh JH. Physiology of the Gastrointestinal Tract. 3rd ed. New York: Raven; 1994, . p. 751-794.

5. Shibata C, Balsiger BM, Anding WJ, Sarr MG. Adrenergic denervation hypersensitivity in ileal circular smooth muscle after small bowel transplantation in rats. Dig Dis Sci. 1997;42:2213-2221.

6. Ohtani N, Balsiger BM, Anding WJ, Duenes JA, Sarr MG. Small bowel transplantation induces adrenergic hypersensitivity in ileal longitudinal smooth muscle in rats. J Gastrointest Surg. 2000;4:77-85.

7. Lyrenas E, Abrahamsson H, Dotevall G. Rectosigmoid motility response to beta-adrenoceptor stimulation in patients with the irritable bowel syndrome. Scand J Gastroenterol. 1985;20:1163-1168.

8. Seiler R, Rickenbacher A, Shaw S, Balsiger BM. alpha- and betaadrenergic receptor mechanisms in spontaneous contractile activity of rat ileal longitudinal smooth muscle. J Gastrointest Surg. 2005;9:227-235.

9. Gordon AR, Siegman MJ. Mechanical properties of smooth muscle. I. Length-tension and force- velocity relations. Am J Physiol. 1971;221:1243-1249.

10. Fox DA, Bass P. Ablation of the myenteric plexus impairs alpha but not beta adrenergic receptor-mediated mechanical responses of rat jejunal longitudinal muscle. J Pharmacol Exp Ther. 1986;239:9-14.

11. Nishizaki K, Nakao K, Ishii H, et al. Induction of neuronal nitric oxide synthase by sympathetic denervation is mediated via alpha 2 -adrenoceptors in the jejunal myenteric plexus. Brain Res. 2003;965:121-129.

12. Sagrada A, Fargeas MJ, Bueno L. Involvement of alpha-1 and alpha-2 adrenoceptors in the postlaparotomy intestinal motor disturbances in the rat. Gut. 1987;28:955-959.

13. Sawaki D, Otani Y, Sekita G, et al. Pheochromocytoma complicated with refractory paralytic ileus dramatically improved with intravenous administration of alpha-adrenergic receptor antagonist, phentolamine. J Clin Gastroenterol. 2003;37(2):194.

14. Lepor H, Rigaud G, Shapiro E, Baumann M, Kodner IJ, Fleshman JW. Muscarinic cholinergic and alpha 2-adrenergic receptors in the epithelium and muscularis of the human ileum. Surgery. 1990;107:461-467.

15. Wikberg JE. Reversal of alpha 1-receptor mediated relaxation in intestinal smooth muscle. Acta Physiol Scand. 1981;111:385-395.

16. Gater PR, Haylett DG, Jenkinson DH. Neuromuscular blocking agents inhibit receptor-mediated increases in the potassium permeability of intestinal smooth muscle. $\mathrm{Br} \mathrm{J}$ Pharmacol. 1985;86:861-868

17. Sakai Y, Daniel EE, Jury J, Fox JE. Neurotensin inhibition of canine intestinal motility in vivo via alpha- adrenoceptors. Can J Physiol Pharmacol. 1984;62:403-411.

18. De Man JG, Moreels TG, De Winter BY, et al. Disturbance of the prejunctional modulation of cholinergic neurotransmission during chronic granulomatous inflammation of the mouse ileum. Br J Pharmacol. 2001;133:695-707.

19. Decktor DL, Pendleton RG, Ensslen ME, Davis MM. Lidamidine inhibits intrinsic contractile patterns of the rat proximal colon. Eur J Pharmacol. 1987;143:213-219.

20. Tarnoky K, Szenohradszky J, Petri G. Changes of small bowel motility and noradrenaline content of the intestinal wall in response to alpha- and beta-adrenergic blockade in dog. Acta Physiol Hung. 1986;67:447-456.

21. Malone ED, Brown DR, Trent AM, Turner TA. Influence of adrenergic and cholinergic mediators on the equine jejunum in vitro. Am J Vet Res. 1996;57:884-890.

22. Wikberg JE. Reversal of alpha 1-receptor mediated relaxation in intestinal smooth muscle. Acta Physiol Scand. 1981;111:385-395.

23. Romanelli L, Amico MC, Palmery M, et al. Role of the cholinergic system and of apamin-sensitive $\mathrm{Ca} 2+$-activated $\mathrm{K}+$ channels on rabbit jejunum spontaneous activity and on the inhibitory effects of adrenoceptor agonists. Auton Autacoid Pharmacol. 2003;23:105-115.

24. Manara L, Croci T, Landi M. Beta 3-adrenoceptors and intestinal motility. Fundam Clin Pharmacol. 1995;9:332-342.

25. Arch JR, Ainsworth AT, Cawthorne MA, et al. Atypical betaadrenoceptor on brown adipocytes as target for anti- obesity drugs. Nature. 1984;309:163-165.

26. Brown KJ, Summers RJ. beta(1)- and beta(3)-adrenoceptor mediated smooth muscle relaxation in hypothyroid rat ileum. Eur J Pharmacol. 2001;415:257-263.

27. Balsiger BM, He CL, Zyromski NJ, Sarr MG. Neuronal adrenergic and muscular cholinergic contractile hypersensitivity in canine jejunum after extrinsic denervation. J Gastrointest Surg. 2003;7:572-582.

28. Ozturk Y, Yildizoglu-Ari N, Ozuari A, Ozcelikay AT, Altan VM Decreased beta-adrenergic responses of rat small intestine due to non- insulin-dependent diabetes. Diabetes Res Clin Pract. 1990;9:123-127.

29. Romanski KW. Ovine model for clear-cut study on the role of cholecystokinin in antral, small intestinal and gallbladder motility. Pol J Pharmacol. 2004;56:247-256.

30. Hansen MB. Small intestinal manometry. Physiol Res. 2002;51:541-556.

31. Wagner J, Nick B, Rohm N, Schumann HJ. On the coexistence of beta 1 - and beta 2 -adrenoceptors in various organs. Arch Int Pharmacodyn Ther. 1981;249:26-38.

32. Manara L, Croci T, Aureggi G, et al. Functional assessment of beta adrenoceptor subtypes in human colonic circular and longitudinal (taenia coli) smooth muscle. Gut. 2000;47:337342.

33. Anthony A. Review article: beta 3-adrenoceptor agonists-future anti-inflammatory drugs for the gastrointestinal tract? Aliment Pharmacol Ther. 1996;10:859-863.

34. Anthony A, Schepelmann S, Guillaume JL, et al. Localization of the beta(beta)3-adrenoceptor in the human gastrointestinal tract: an immunohistochemical study. Aliment Pharmacol Ther. 1998;12:519-525. 